\title{
Высокоэффективные фотоэлектрические модули с концентраторами солнечного излучения
}

\author{
() А.В. Чекалин, А.В. Андреева, Н.Ю. Давидюк, Д.А. Малевский, П.В. Покровский, Н.С. Потапович, \\ Н.А. Садчиков, В.М. Андреев
}

Физико-технический институт им. А.Ф. Иофффе РАН, Санкт-Петербург, Россия

E-mail: chekalin@mail.ioffe.ru

Поступило в Редакцию 27 марта 2020 г.

В окончательной редакции 27 марта 2020 г.

Принято к публикации 1 апреля 2020г.

\begin{abstract}
Разработаны и изготовлены высокоэффективные концентраторные фотоэлектрические модули, включающие линзовую панель на основе 32 линз Френеля $(12 \times 12 \mathrm{~cm}$ каждая); 32 каскадных солнечных элемента с вторичными концентраторами в виде фоконов; теплоотводящие электроизолирующие платы на основе алюмооксидной керамики, размещенные на тыльном алюминиевом основании. При измерении модуля площадью $0.46 \mathrm{~m}^{2}$ под импульсным имитатором солнечного излучения (AM1.5D, $1000 \mathrm{~W} / \mathrm{m}^{2}$ ) получено значение КПД, равное $32.3 \%$. В субмодуле площадью $144 \mathrm{~cm}^{2}$ получен КПД $33.9 \%$.
\end{abstract}

Ключевые слова: концентраторный фотоэлектрический модуль, линза Френеля, каскадный солнечный элемент, фокон.

DOI: 10.21883/PJTF.2020.13.49586.18314

Перспективы широкого применения концентраторных фотоэлектрических модулей (КФЭМ) в наземной солнечной энергетике определяются высокой эффективностью, снижением более чем в 500 раз площади и стоимости солнечных элементов пропорционально кратности концентрирования солнечного излучения и увеличением удельного (на единицу площади КФЭМ) энергосъема благодаря высокому КПД, высокой температурной стабильности КПД и использованию систем слежения за Солнцем [1-4]. Каскадные солнечные элементы (КСЭ) имеют максимальные значения КПД $>40 \%$ при кратности концентрирования солнечного излучения более 500 „солнц“, а фотоэлектрические модули на основе этих КСЭ и концентраторов солнечного излучения обеспечивают значения КПД более $30 \%$ в наземных условиях солнечного облучения (AM1.5D).

Увеличение оптической эффективности концентраторов солнечного излучения достигается при осуществлении двухстадийного концентрирования. В качестве первичных концентраторов наибольшее распространение получили линзы Френеля, изготавливаемые по технологии „силикон на стекле“ $[1-5]$, согласно которой френелевский профиль создается в тонком слое (менее $0.5 \mathrm{~mm}$ ) силикона с последующей его полимеризацией на стеклянном листе. В качестве вторичных концентраторов обычно используются конические отражатели, изготовленные либо из зеркально полированного листового алюминия, либо из стекла с полированными боковыми поверхностями [6-10].

В настоящей публикации приводятся результаты разработки концентраторных фотоэлектрических модулей (с размерами фронтальной поверхности $96 \times 48 \mathrm{~cm}$ ), состоящих из 32 субмодулей с размером фронтальной поверхности $12 \times 12 \mathrm{~cm}$ каждый.

Элементами субмодуля являются (рис. 1) первичный концентратор (линза Френеля) размером $12 \times 12 \mathrm{~cm} \mathrm{c}$ фокусным расстоянием $23 \mathrm{~cm}$; вторичный концентратор (фокон), выполненный из листового алюминия в виде перевернутой усеченной пирамиды; каскадный солнеч-

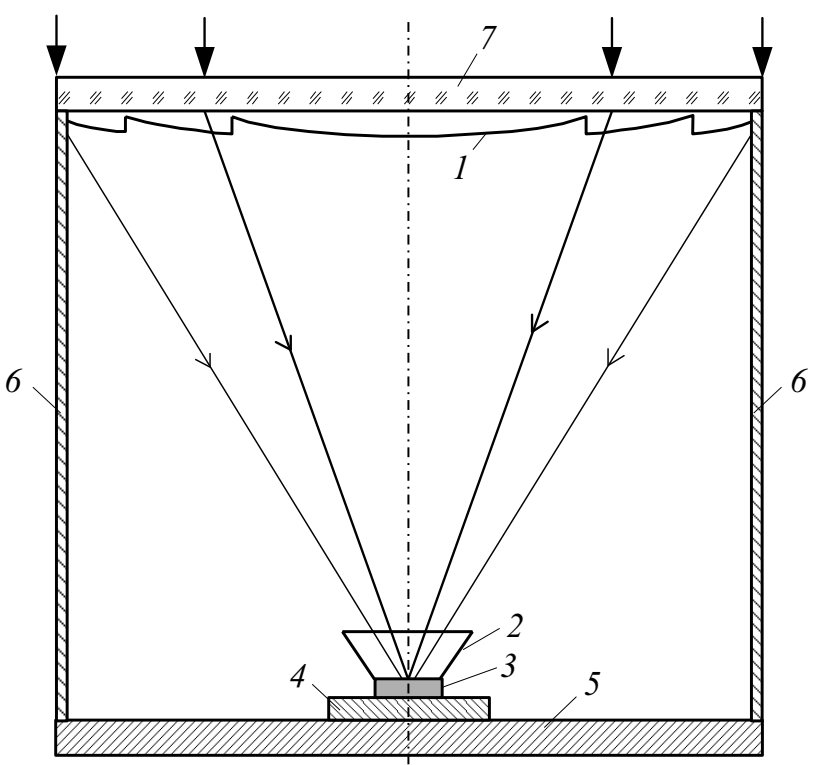

Рис. 1. Конструкция концентраторного фотоэлектрического субмодуля. 1 - линза Френеля, $2-$ фокон, 3 - каскадный солнечный элемент, 4 - теплоотводящая электроизолирующая плата, 5 - алюминиевое основание, $6-$ боковые стенки субмодуля, 7 - стекло. 
Таблица 1. Значения параметров двух субмодулей на основе единичных линз Френеля $(12 \times 12 \mathrm{~cm})$

\begin{tabular}{c|c|c|c|c|c}
\hline Тип модуля & $I_{s c}, \mathrm{~A}$ & $V_{o c}, \mathrm{~V}$ & $P_{\mathrm{MPP}}, \mathrm{W}$ & $F F, \%$ & КПД, \% \\
\hline Без фокона & 1.8785 & 3.0812 & 4.62 & 81.37 & 32.1 \\
С фоконом & 1.9045 & 3.0827 & 4.88 & 83.06 & 33.9
\end{tabular}

Пр и ме чан и е. $I_{s c}-$ ток короткого замыкания, $V_{o c}-$ напряжение холостого хода, $P_{\text {MPP }}-$ мощность в оптимальной точке вольтамперной характеристики, $F F-$ фактор заполнения нагрузочной характеристики, КПД - коэффициент полезного действия.

ный элемент на основе трехпереходной гетероструктуры $\mathrm{GaInP} / \mathrm{GaAs} / \mathrm{Ge}$ с размером фоточувствительной поверхности $5.5 \times 5.5 \mathrm{~mm}$; теплоотводящая электроизолирующая плата, выполненная на основе алюмооксидной керамики; основание модуля, выполненное из алюминиевого листа; боковые стенки, полученные экструзией алюминиевого профиля.

КСЭ в составе модулей имеют КПД $42 \pm 1 \%$. При этом снижение КПД КСЭ при увеличении температуры от -20 до $+80^{\circ} \mathrm{C}$ составляет $0.05 \%$ на $1^{\circ} \mathrm{C}$.

Фоконы изготавливались из листового алюминия с внутренней зеркальной поверхностью. Размер входной апертуры фокона составлял $16 \times 16 \mathrm{~mm}$ при высоте $15 \mathrm{~mm}$ и размере выходной апертуры $4.5 \times 4.5 \mathrm{~mm}$. Расстояние между выходной апертурой фокона и поверхностью солнечного элемента устанавливалось порядка $0.1 \mathrm{~mm}$.

Чипы солнечных элементов припаивались в вакуумной печи на теплоотводящие электроизолирующие платы размером $2 \times 2 \mathrm{~cm}$, выполненные на основе алюмооксидной керамики толщиной $380 \mu \mathrm{m} \mathrm{c}$ медным двусторонним покрытием. Общая толщина плат составляла около $1 \mathrm{~mm}$. Платы закреплялись на основании, выполненном из листового алюминия толщиной $3 \mathrm{~mm}$. Перегрев солнечных элементов относительно температуры $\mathrm{Al}$-основания составил $22-25^{\circ} \mathrm{C}$ в рабочем режиме при освещении КФЭМ прямым солнечным излучением мощностью $850 \mathrm{~W} / \mathrm{m}^{2}$.

На первом этапе были разработаны субмодули на основе одной линзы Френеля. Как видно из табл. 1, получено увеличение КПД субмодуля на основе единичной линзы Френеля от $32.1 \%$ (без фокона) до $33.9 \%$ (с фоконом). Это увеличение КПД достигнуто за счет увеличения фототока $\left(I_{s c}\right)$ и увеличения фактора заполнения $(F F)$ нагрузочной вольт-амперной характеристики. Увеличение фототока обеспечено за счет улучшения собирания солнечного излучения, отражаемого стенками фокона, а увеличение $F F$ связано с улучшением равномерности облучения солнечного элемента в модуле с фоконом.

На втором этапе были разработаны и исследованы полноразмерные концентраторные модули, включающие панели площадью $0.46 \mathrm{~m}^{2}$, состоящие из 32 линз Френеля, расположенных вплотную, и электрогенерирующие

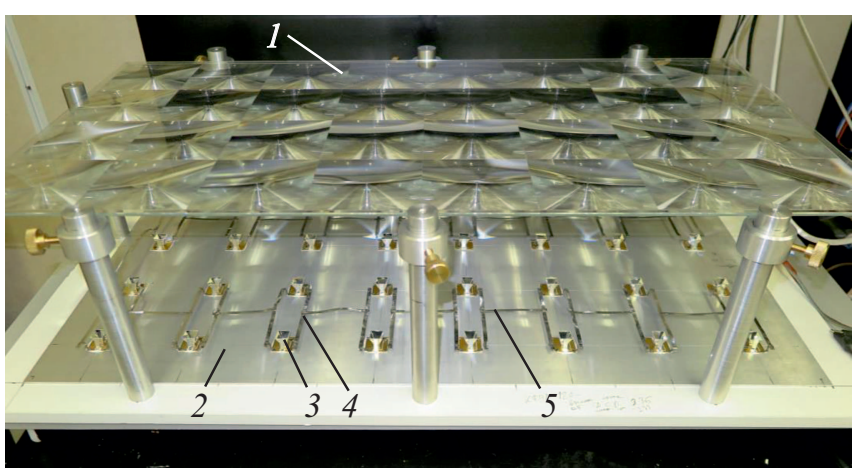

Рис. 2. Концентраторный фотоэлектрический модуль площадью $0.46 \mathrm{~m}^{2}$ на основе 32 линз Френеля и 32 каскадных солнечных элементов с фоконами. 1 - линзовая панель, 2 - основание модуля, 3 - фокон, 4, 5 - коммутирующие шины.

Таблица 2. Значения параметров полноразмерного концентраторного модуля площадью $0.46 \mathrm{~m}^{2}$

\begin{tabular}{c|c|c|c|c}
\hline$I_{s c}, \mathrm{~A}$ & $V_{o c}, \mathrm{~V}$ & $P_{\mathrm{MPP}}, \mathrm{W}$ & $F F, \%$ & КПД, \% \\
\hline 3.823 & 49.585 & 148.87 & 78.53 & 32.3
\end{tabular}

панели, состоящие из 32 каскадных солнечных элементов (с установленными на них фоконами), смонтированных через теплопроводящие электроизолирующие платы на $\mathrm{Al}$-основаниях размером $1 \times 0.5 \mathrm{~m}$. Электрическая коммутация солнечных элементов имеет параллельнопоследовательную схему соединения и осуществлена с помощью луженых медных шин шириной $5 \mathrm{~mm}$ и толщиной $0.2 \mathrm{~mm}$. Линзовая и электрогенерирующая панели соединены в модуле с помощью четырех боковых стенок шириной $230 \mathrm{~mm}$, полученных экструзией алюминиевого профиля.

На рис. 2 приведена фотография модуля (без боковых стенок), установленного в рабочем поле импульсного имитатора солнечного излучения (со спектром AM1.5D), обеспечивающего энергетическую освещенность $1000 \mathrm{~W} / \mathrm{m}^{2}$. Измерения проводились в лабораторных условиях при температуре окружающей среды $T=24 \pm 1^{\circ} \mathrm{C}$.

На рис. 3 приведена вольт-амперная характеристика модуля, а в табл. 2 представлены результаты измерений электрических характеристик КФЭМ. В результате измерений модуля установлено, что максимальная электрическая мощность, генерируемая модулем в режиме оптимальной нагрузки, составляет $148.9 \mathrm{~W}$ при КПД преобразования солнечного излучения, равном $32.3 \%$.

Были проведены испытания разработанных модулей на воздействие факторов окружающей среды: перепады давления, дождь, ветер, град и др.

Для защиты герметичных модулей от перепадов давления в стенки модулей были вставлены мембранные фильтры GORE PolyVent High Flow, обеспечивающие 


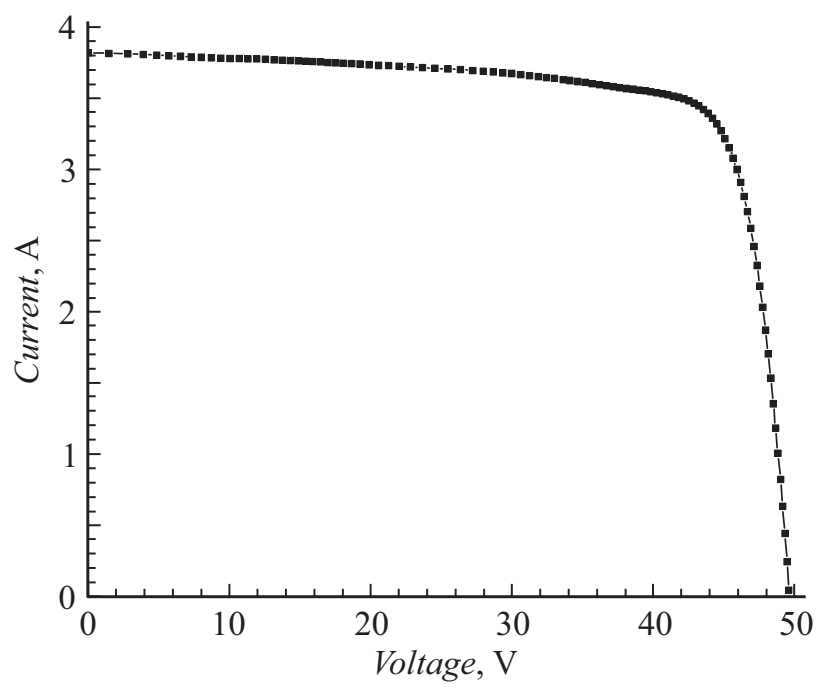

Рис. 3. Световая вольт-амперная характеристика концентраторного фотоэлектрического модуля площадью $0.46 \mathrm{~m}^{2}$, демонстрирующая достижение КПД $32.3 \%$ (AM1.5D, $\left.1000 \mathrm{~W} / \mathrm{m}^{2}\right)$.

выравнивание давления внутри и снаружи модуля: снижение давления внутри модуля при уменьшении температуры внутри модуля и возрастание давления при увеличении температуры. Фильтры GORE являются гидрофобными, обеспечивают свободное прохождение воздуха, но препятствуют проникновению в модуль капель воды и пыли.

Испытания модулей на воздействие механических нагрузок (ветер, снег) были проведены на установке, обеспечивающей давящую нагрузку, имитирующую воздействие ветра и снега. В результате испытаний модули продемонстрировали устойчивость до давлений более $2400 \mathrm{~Pa}$, эквивалентных воздействию ветра до ураганных скоростей более $50 \mathrm{~m} / \mathrm{s}$.

Испытания на воздействие града, проведенные с использованием градострельной „пушки“, показали устойчивость модулей к ударам градин диаметром до $30 \mathrm{~mm}$ при их скорости более $22 \mathrm{~m} / \mathrm{s}$.

Таким образом, выполненные испытания показали устойчивость разработанных КФЭМ к воздействию условий окружающей среды, что должно обеспечить большой срок службы модулей, позволяющий осуществить выработку „солнечной“ электроэнергии в количестве, обеспечивающем окупаемость затрат на изготовление модулей.

Разработанные высокоэффективные модули имеют большие перспективы практического применения вследствие существенного увеличения удельной мощности солнечных батарей до $300 \mathrm{~W} / \mathrm{m}^{2}$ (в условиях облучения $\left.\mathrm{AM} 1.5 \mathrm{D}, 1000 \mathrm{~W} / \mathrm{m}^{2}\right)$. Слежение за Солнцем в концентраторных фотоэнергосистемах увеличивает удельную (на единицу мощности системы, $\mathrm{kW} \cdot \mathrm{h} / \mathrm{kW}_{\text {peak }}$ ) энерговыработку, что обеспечивает дополнительное снижение стоимости солнечного электричества при сравнимой (с солнечными батареями без слежения) стоимости установленной мощности солнечных батарей.

\section{Финансирование работы}

Исследование выполнено за счет гранта Российского научного фонда (проект № 17-79-30035).

\section{Конфликт интересов}

Авторы заявляют, что у них нет конфликта интересов.

\section{Список литературы}

[1] Andreev V.M., Grilikhes V.A., Rumyantsev V.D. // Photovoltaic conversion of concentrated sunlight. John Wiley \& Sons Ltd, 1997. $294 \mathrm{c}$.

[2] Alferov Zh.I., Andreev V.M., Rumyantsev V.D. III-V heterostructures in photovoltaics // Concentrator photovoltaics / Eds A. Luque López, V.M. Andreev. Springer Ser. in Optical Sciences. Berlin-Heidelberg: Springer-Verlag, 2007. V.130. P. 25-50.

[3] Green M.A., Dunlop E.D., Hohl-Ebinger J., Yoshita M., Kopidakis N., Ho-Baillie A.W.Y. // Prog. Photovolt. 2019. V. 28. N 1. P. 3-15. DOI: $10.1002 /$ pip.3228

[4] Dominguez C., Antón I., Sala G., Askins S. // Prog. Photovolt. 2013. V. 21. N 7. P. $1478-1488$. DOI: $10.1002 /$ pip.2227

[5] Grilikhes V.A., Shvarts M.Z., Soluyanov A.A., Vlasova E.V., Andreev V.M. The new approach to design of Fresnel lens sunlight concentrator // Proc. of the 4th Int. Conf. on solar concentrators for the generation of electricity or hydrogen. El Escorial, Spain, 2007. P. 49-52.

[6] Victoria M., Herrero R., Domiinguez C., Antón I., Askins S., Sala G. // Prog. Photovolt. 2013. V. 21. N 3. P. 308-318. DOI: $10.1002 /$ pip. 1183

[7] Araki K., Kondo M., Uozumi H., Yamaguchi M. Experimental proof and theoretical analysis on effectiveness of passive homogenizers to $3 \mathrm{~J}$ concentrator solar cells // Proc. of the 3rd World Conf. on photovoltaic and energy conversion. Osaka, Japan, 2003. V. 1. P. 853-856.

[8] Jaus J., Nitz P., Peharz G., Siefer G., Schult T., Wolf O., Passig M., Gandy T., Bett A.W. Second stage reflective and refractive optics for concentrator photovoltaics // 33rd IEEE Photovoltaic Specialists Conf. San Diego, USA, 2008. P. 1-5.

[9] Wiesenfarth M., Anton I., Bett A.W. // Appl. Phys. Rev. 2018. V. 5. N 4. P. 041601 . DOI: $10.1063 / 1.5046752$

[10] Shanks K., Senthilarasu S., Mallick T.K. // Renewable Sustainable Energy Rev. 2016. V. 60. P. 394-407. DOI: 10.1016/j.rser.2016.01.089 